\title{
Conservation Education Impacts of Animal Ambassadors in Zoos
}

\author{
Megan Marie Clifford-Clarke ${ }^{1,2,3, *}$, Katherine Whitehouse-Tedd ${ }^{1}$ (D) and Clare Frances Ellis ${ }^{3,4}$ (D) \\ 1 School of Animal, Rural and Environmental Sciences, Nottingham Trent University, \\ Southwell NG25 0QF, UK; katherine.whitehousetedd@ntu.ac.uk \\ 2 Derby College, University of Derby, Derbyshire DE7 6DN, UK \\ 3 Education, Conservation and Research, Twycross Zoo, Atherstone CV9 3PX, UK; clare.f.ellis@gmail.com \\ 4 University Centre Reaseheath, Reaseheath College, Nantwich CW5 6DF, UK \\ * Correspondence: megan_clifford@hotmail.com
}

Citation: Clifford-Clarke, M.M.; Whitehouse-Tedd, K.; Ellis, C.F. Conservation Education Impacts of Animal Ambassadors in Zoos. J. Zool. Bot. Gard. 2022, 3, 1-18. https:// doi.org/10.3390/jzbg3010001

Academic Editors:

Michel Saint-Jalme and

Sarah Spooner

Received: 28 September 2021

Accepted: 14 December 2021

Published: 22 December 2021

Publisher's Note: MDPI stays neutral with regard to jurisdictional claims in published maps and institutional affiliations.

Copyright: (C) 2021 by the authors. Licensee MDPI, Basel, Switzerland. This article is an open access article distributed under the terms and conditions of the Creative Commons Attribution (CC BY) license (https:// creativecommons.org/licenses/by/ $4.0 /)$.
Abstract: To mitigate the effects of anthropogenic environmental impacts, conservation education (CE) aims to increase public awareness of biodiversity and encourage the uptake of pro-environmental behaviours (PEB). One way of achieving this goal is the use of controlled animal interactions with animal ambassadors to promote CE goals. This study aimed to determine how differing experiences with ambassador Humboldt penguins (Spheniscus humboldti) affected visitors' knowledge of conservation actions (CA) and their likelihood to perform PEBs in a UK zoo. A quasi-experimental repeated measures questionnaire was used to investigate this aim. Visit types were categorised as (a) 'penguin parade', (b) 'animal encounter', (c) 'exhibit viewing' and (d) a 'control' groups. A Kruskal-Wallis test was used to determine if responses to rating scale items related to PEBs differed according to experience. No significant $(p>0.05)$ differences were detectable between groups. Qualitative data provided in open ended questions relating to CAs were coded into themes and the percentage of responses were calculated for each theme. Whilst the 'exhibit viewing' group mentioned sustainable fish significantly more ( $p=0.017)$ than the 'control' group, no significant difference was found for any other pair-wise comparison ( $p>0.05$ in all cases). Overall, this study highlights that zoo visitors gained specific conservation-based knowledge and had higher behavioural intentions towards PEBs than they previously had. However, no evidence was found to suggest that animal encounters improved CE outcomes. To ensure best practice is followed and CE outcomes are considered equally alongside ambassador animal welfare concerns, further research is recommended.

Keywords: animal ambassadors; pro-environmental behaviours; conservation actions; conservation education

\section{Introduction}

Conservation education (CE) aims to increase public awareness of biodiversity, including the environmental issues facing the natural world; $\mathrm{CE}$ activities therefore often involve imparting knowledge of actions that can be undertaken to mitigate these problems [1-3]. Given that the unsustainable consumption of natural resources is a significant factor in climate change and biodiversity loss [4], changing people's behaviours and encouraging them to think carefully about their consumption choices may make a significant difference to reducing anthropogenic environmental impacts [5]. Conservation education is subsequently aligned to the rationale that an increased environmental understanding and awareness promotes more positive attitudes and emotions toward conservation. This can lead to increased knowledge of conservation actions (CA), actions that can generally support the conservation of biodiversity such as 'protected areas' or 'sustainable resourcing' and are more likely to translate into pro-environmental behaviours (PEBs) that individuals are able to perform such as 'recycling' or 'buying sustainable fish' [6,7]. 
Attracting over 700 million visits a year worldwide [8], zoos (Zoo Definition: 'A place where live animals are kept, studied, bred and exhibited to the public' [9]) are in an opportune position to reach large audiences with CE. Carefully designed CE has the potential to also enhance visitor experiences as well as encourage pro-environmental behaviours [10] such that many zoos include the delivery of $C E$ in their mission statements [11]. The zoo-based delivery of $\mathrm{CE}$ ranges from interpretive signage and enclosure design to animal presentations and encounters [12]. Animal presentations and feeding times utilise a 'free-choice' learning strategy [13-16], allowing visitors to attend spoken presentations and encounters at their own discretion and convenience. This provides the chance to closely observe, touch or feed the animals [12] and may provide unique learning and entertainment opportunities [17].

Controlled animal interactions, where staff supervise experiences where visitors can become close to or physically interact with animals more so than is allowed during ordinary visits, are often used by zoos as part of their efforts to reach CE goals [1]. In addition to generating vital revenue for establishment running costs and conservation efforts, these interactions are anticipated to facilitate increased visitor connection to wildlife, subsequently enhancing the delivery of $\mathrm{CE}$ [18]. To appeal to large audiences, such encounters frequently use popular charismatic flagship species (A flagship species possesses popular traits that appeal to a target audience and are used as target specific for conservation marketing due to their charisma and appeal [19]), which are handled or trained specifically for this use and are termed animal 'ambassadors' [20] or 'programme' animals [21]. The use of animal ambassadors in visitor experiences has been found to increase visitor empathy toward animals, improve conservation learning outcomes and encourage pro-environmental behaviours amongst visitors [22-28]. Conservation education involving animal ambassadors also involves greater visitor engagement with zoo staff, who have been found to guide conversation to better $\mathrm{CE}$ outcomes and have a greater impact on visitor learning than what can be achieved through passive visitor learning alone [29-31]. For example, written interpretive information may be ignored during non-interactive experiences as visitor attention is typically directed towards the live animal [32].

However, the values of visitors related to conservation have not always increased from baseline values following animal interactions $[24,33]$ and there are concerns that using charismatic species as ambassadors may lead to a distraction from the learning goals [26] or inappropriate messaging [1]. Ethical and welfare concerns have also been raised for animal ambassadors where increased aggression, avoidance and stress behaviours have been observed in response to visitors, including stereotypies, unusual defecation, huddling and increased vigilance [34,35].

Zoo visitors frequently place higher importance on entertainment value than learning (e.g., see Ballantyne and Packer, 2016 [36] which surveyed zoo visitors in four different countries) and conclusive evidence of the CE impact of zoos is somewhat limited in the literature. Moreover, in a study involving 170 zoos across 48 countries, only $15 \%$ of zoos reported using both formal (including questionnaires, surveys and structured interviews) and informal (including casual conversations and feedback, personal opinion and subjective observations) measures of visitor learning, with most zoos relying on less accurate informal data [37], possibly due to limited resources. Nonetheless, the importance of pro-environmental behaviours is becoming better understood by the public and zoo visitors appear to be increasingly choosing to engage with CE [38,39].

The knowledge-attitude-behaviour link which forms a key focus of recent CE evaluations $[24,33,40]$ has, to date, not been investigated in relation to the use of animal ambassador animals in zoos. Likewise, knowledge or attitudinal change following a zoo $\mathrm{CE}$ experience are not necessarily predictive or reflective of behavioural change. Where follow up studies have been conducted, findings for reported behavioural intention and actual behavioural outcomes in relation to visitors have been variable [41-43]. For example, Hughes [42] found that PEB intentions including composting, using reusable containers and purchasing products with less packaging were actioned by the majority of visitors 
three months after a CE experience, whereas Foster [41] found behaviours such as 'riding a bike', 'walking to work' or 'using public transport' were not, possibly due to difficulties in implementing these in modern lifestyles. Realised action may be linked to the type of PEB, as Foster [41] highlights that those behaviours most likely to be actioned were easy to do and could save money, but more research is needed to clarify this. Many studies use the Theory of Planned Behaviour [44] as a focal theory for researching such topics. According to this theory, social norms, perceived impacts of performing a behaviour and a person's perceived control over the behaviour influences their likelihood to perform it $[45,46]$. Some of this research has revealed a significant link between intention and behaviour $[47,48]$. Nonetheless, the call for more research on behavioural intentions is prominent in the current literature [49-51].

Our study aimed to begin to address this gap in behavioural intention by utilising varying zoo visitor experiences involving ambassador Humboldt penguins (Spheniscus humboldti) to investigate the influence of CE delivery methods on visitor intention to perform specific pro-environmental behaviours. The study was focused around three main questions: (1) Does visitor intention to perform PEBs change following their zoo visit? If so, (2) Was this change affected by the experiences during the zoo visit (visit type)? and (3) Does visitor knowledge of conservation actions (CA) change following their zoo visit?

\section{Methods}

Visitors to a medium-large UK zoological facility (Twycross zoo, East Midlands, UK) were invited to participate in a repeated measures quasi-experimental study, whereby data were collected via questionnaires from participants on entry to and again on exit from the zoo [41,52]. Visitors were asked questions about their current practice of PEB, their intent to perform such behaviours following their visit and their knowledge of CA in relation to the target species (Humboldt penguins).

\subsection{Participant Recruitment}

To explore the impact that different types of experiences at the zoo may have on intention to perform PEBs, four types of zoo visits were identified prior to the start of the study and participants were categorised into one of the four groups according to the visit type that they had chosen to engage with during their visit. Visit types targeted for investigation included: (a) 'penguin parade', participants observe trained penguins walking out from their enclosure into a separate viewing area, along with a 5-10 min educational talk delivered by education staff (referred to as a Penguin Parade by the zoo) but no physical penguin-visitor interaction occurs, (b) 'encounter', participants take part in a Penguin Encounter in which small groups of 1-4 visitors accompany keeping staff into the enclosure during a Penguin Parade and are able to interact with the penguins by hand-feeding them and asking questions of the staff, (c) 'exhibit viewing', participants make a passive observation of the penguins on exhibit outside of the Penguin Parade times, with voluntary use of the available interpretation material provided around the enclosure and no access to staff or (d) 'control' group of participants that do not view the penguins or their enclosure during their zoo visit. Visitors were not informed of these classifications of visit type and were free to choose how they engaged with zoo CE opportunities during their visit, although 'encounter' participants were required to pre-book this activity prior to their arrival at the zoo, according to standard zoo operations. For all other participants, it was unknown until they completed the post-visit questionnaire which group they would fall into. All participants had equal access to the zoo grounds and advertisement of zoo talk times, including the penguin parade, and this information was routinely pointed out to them by zoo staff upon ticket purchase/collection.

A convenience sampling strategy was used to collect visitor data between February and March 2018. Except for the 'encounter' group, visitors were approached by the first author and a research assistant as they entered the zoo and were invited to participate; every passing visitor possible was approached and surveyed upon giving consent. Participating 
visitors were issued a unique number to identify participants anonymously. Since Penguin Encounters were limited to eight participants daily (max. 4 per encounter session, with twice daily sessions) the convenience sampling strategy used for other groups was not predicted to yield sufficient data for this group. Therefore, participants who took part in an encounter were identified on each sampling day via their pre-existing booking for this experience type and were therefore specifically approached upon their registration at the zoo, although participation was still voluntary. At the post-visit survey point, participants were asked to return to the survey point at the end of their visit and were identified using their unique number provided during the pre-visit questionnaire. They were asked to provide information about the type of experience they had to enable classification during data analysis (as seen in Mellish et al., 2016 [38]).

Only Encounter experiences incurred a fee payable in addition to the zoo entrance fee. Penguin encounters and parades occurred simultaneously and participants from both groups heard the same presentation from an education team ranger. 'Penguin parade' visitor groups were able to observe other participants and non- participants involved in an encounter whilst observing the parade. Although presentations were not fully scripted and some information and delivery methods may have varied between Education staff, the zoo prescribed key themes to be covered; sustainable fishing and reducing plastic waste were always included in the presentation. In addition, participants engaged in an encounter also had a zookeeper engaging in a non-scripted dialogue with them during the feeding activity. Static interpretive material was available for all participants to utilise (Figure 1) but was not available to participants in the 'control' group.

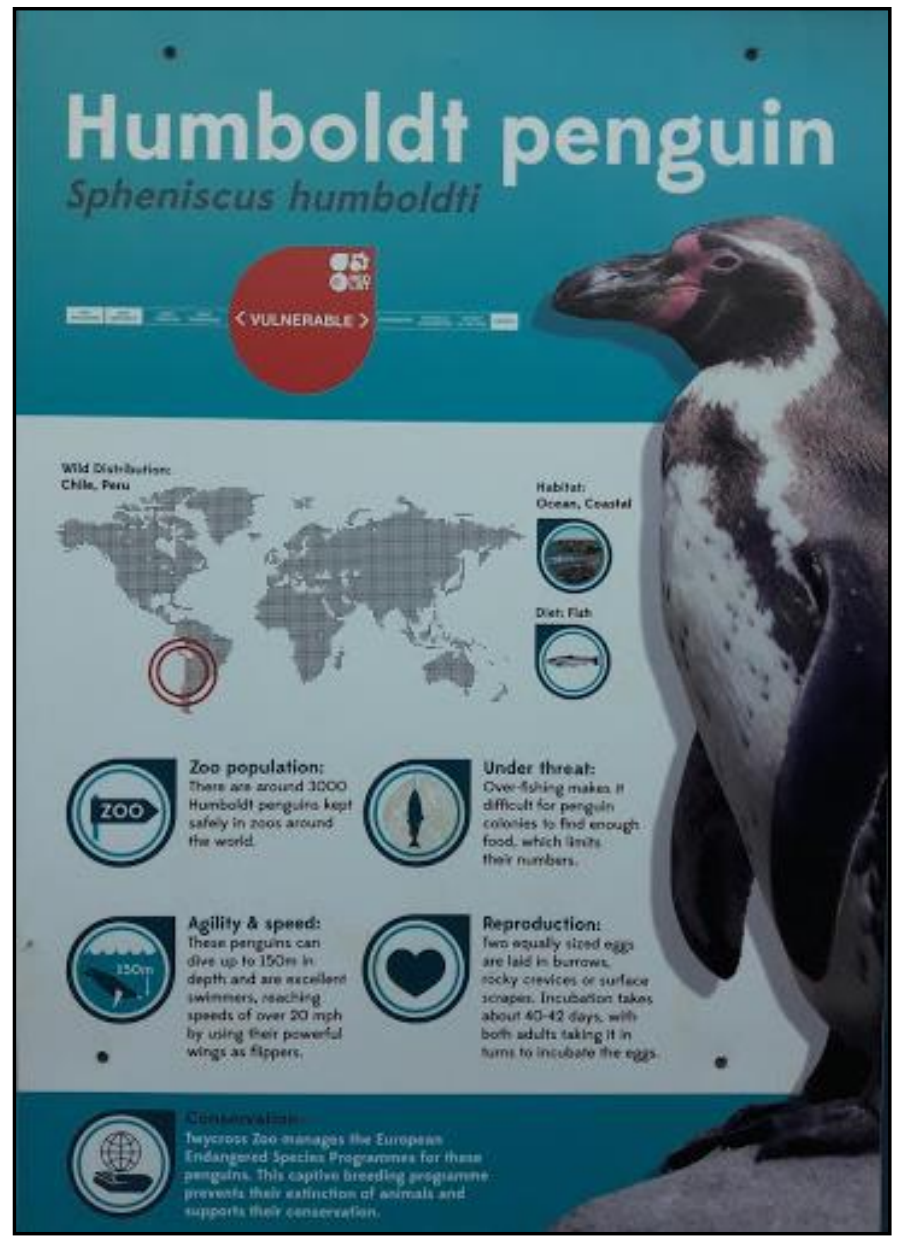

Figure 1. Interpretive signage available to all visitors at the Humboldt penguin enclosure at Twycross Zoo. 


\subsection{Survey Instrument}

A questionnaire was used to determine participant behavioural actions prior to (previsit) and behavioural intentions following (post-visit) their visit to Twycross Zoo. A pilot test carried out over two days in February 2018 with 30 zoo visitors was used to refine the sampling and surveying methods. No question items were identified as problematic (i.e., based on pilot-participant understanding, ease of answering and time to answer). Each questionnaire took approximately five to ten minutes to complete.

Pre- and post-visit questionnaires included a mixture of rating scale items and openended questions (Table 1). Visitors responded to statements about specific achievable PEBs that could be directly performed by all zoo visitors, as per Hughes [42], using a five-point scale. Self-reported measures of visitor engagement with select PEBs were measured before their visit using a five-point rating-scale ( $1=$ Always, 2 = Sometimes, $3=$ Unsure, 4 = Rarely, $5=$ Never). These were compared to post-visit reports of likelihood to perform those same behaviours (as per Foster [41]; Miller et al. [28]) on another five-point scale ( 1 = Very Likely, 2 = Likely, 3 = Unsure, 4 = Unlikely, 5 = Highly Unlikely), as a measure of intent to perform PEB. Open ended responses were also included to gain a greater understanding of visitor views of conservation [53] in both pre- and post-visit questionnaires. Some additional questions were included in the pre-visit questionnaire about non-target species to reduce risk of priming.

Table 1. Statements in a repeated measure questionnaire used to assess the changes in behavioural intention and conservation action knowledge in visitors to a zoo following a penguin-related conservation education experience.

Statements rated on a five-point scale (where $\mathbf{1}=$ Always and $\mathbf{5}=$ Never): Pre-visit
Questionnaire.
How often do you undertake the following?
Buy sustainable fish/encourage others to so
Volunteer for conservation
Tell friends how they can help to conserve wildlife
Use re-usable shopping bags
Donate money to conservation
Questionnaire.
How likely are you to undertake the following?
Buy sustainable fish/encourage others to so
Volunteer for conservation
Tell friends how they can help to conserve wildlife
Use re-usable shopping bags
Donate money to conservation
Open Ended Items: Pre-visit Questionnaire
Can you think of any specific conservation actions you can take for the Snow Leopard?
Can you think of any specific conservation actions you can take for the Ring-tailed Lemur?
Can you think of any specific conservation actions you can take for the Humboldt Penguin?
Are there any other specific conservation actions you already do?
Open Ended Items: Post-visit Questionnaire
Can you think of any specific conservation actions you can take for the Humboldt Penguin?
Are there any other specific conservation actions you have learned about today?

\subsection{Data Collection}

Questionnaires were administered via a face-to-face interview at the zoo entrance, but a self-reported response strategy was used to minimise social desirability bias among our sample population [54]. As such, questions were read aloud by researchers and participants were asked to self-record their responses on individual answer sheets. Postvisit questionnaires were delivered at the point of visitor exit using the same data collection method. 


\subsection{Ethical Considerations}

This research was approved by the ethics committees of Twycross Zoo and Nottingham Trent University's School of Animal, Rural and Environmental Sciences (ARE695). Participation was voluntary and participants were informed of the study purposes but were unaware of the study prior to their visit. Each participant was over the age of 18 years and gave written consent to use their answers in the study as well as confirming their understanding of their right to withdraw. No participants subsequently requested their data be withdrawn. Upon completion of the pre-visit questionnaires, participants were provided with a unique identification number for matching to post-visit questionnaires. This allowed for anonymous matching of pre-visit answers to post-visit answers.

\subsection{Data Analysis}

All analyses were performed using IBM SPSS Software version 26 [55] and significance was set at $p<0.05$. Sample characteristics (age and gender) were compared between the four experience types using a Chi-squared test of association. Reliability testing of PEB rating-scale items from all participants as well as responses from each experience type respectively were performed using Cronbach's alpha test of internal consistency and the Keiser-Meyer-Olkin (KMO) measure of sampling adequacy, respectively, to determine how data would be analysed. Cronbach's alpha and the Kaiser-Meyer-Olkin measure both returned results below the threshold for acceptability $(<0.7)$ except for the 'encounter' group. Thus, further analysis was restricted to a question-by-question analysis instead of via a summation of scores and factor analysis.

A Kruskal-Wallis test was used to determine if responses to rating scale items differed according to experience type on a question-by-question basis in either the pre- or post-visit responses. Qualitative data provided in open ended questions relating to CAs were coded into themes (Table 2), a method reflected in Moss et al. (2014) [56]. Two researchers initially coded the data independently to generate an inter-rater variability model for validation of coding, as seen in Moss et al., (2014) [56].

Table 2. Overarching themes used to categorise the responses to open ended questions and their definitions used as criteria to determine how the answers were categorised.

\begin{tabular}{|c|c|}
\hline Overarching Theme & Description \\
\hline No valid answer & Participant gave no valid answer. \\
\hline Climate Change & $\begin{array}{c}\text { Any answer relating to climate change, global warming or major } \\
\text { contributing effects such as emissions. }\end{array}$ \\
\hline Sustainable fishing & Any answer relating to sustainable fishing/reducing fishing/eating less fish. \\
\hline Reduce, Reuse, Recycle & $\begin{array}{c}\text { Any answer relating to reducing consumptions, e.g., purposing } \\
\text { non-recyclable items, recycling household waste. }\end{array}$ \\
\hline Ex situ conservation breeding & Mention of ex situ conservation including breeding programmes in zoos \\
\hline $\begin{array}{c}\text { Charitable or general support of zoos and } \\
\text { aquariums }\end{array}$ & $\begin{array}{l}\text { Support of conservation charities (companion animal sponsorship/support } \\
\text { was excluded as not related to conservation). This includes memberships } \\
\text { and adoptions of animals at such establishments. Had to suggest actual } \\
\text { support for that organisation, including financial support or general support } \\
\text { without specific financial investment. }\end{array}$ \\
\hline Ecotourism & Mention of or active support/participation in ecotourism. \\
\hline Hunting ban/guano usage ban & Mention of bans on hunting of penguins, inclusive of the use of guano. \\
\hline Habitat protection/Environmental conservation & $\begin{array}{l}\text { Protection of native habitats and natural wild ranges of the species, } \\
\text { conservation of the environment, in situ conservation }\end{array}$ \\
\hline $\begin{array}{l}\text { Education/ } \\
\text { awareness }\end{array}$ & $\begin{array}{l}\text { Any mention of learning about conservation, raising awareness of } \\
\text { conservation or spreading knowledge/awareness of conservation. }\end{array}$ \\
\hline Regulations & $\begin{array}{c}\text { Regulatory rules/patrols/groups that aid penguin conservation. The } \\
\text { exception is laws/regulations relating to fishing which are classified under } \\
\text { sustainable fishing. }\end{array}$ \\
\hline $\begin{array}{l}\text { Avoiding removal of animals from natural } \\
\text { habitat }\end{array}$ & Answers relating to not removing penguins from their natural habitat. \\
\hline
\end{tabular}


Answers were further categorised into whether the visitor had identified a general overarching theme or an action that they could personally act upon, i.e., any individual could personally contribute, physically or financially, toward performing this action. To be a personally achievable goal, the individual must have responded in a way that indicated their involvement specifically, e.g., the use of first-person tense or an indication that it was them performing the action. For example, answers such as 'breeding programmes' were excluded from the personally achievable category as whilst they are valid actions, they are performed by other individuals/organisations. A Chi-squared test was used to test for difference between visit types in post-visit responses that either identified a personal or an overarching theme.

Where multiple CAs were specified, each valid answer was counted and given a theme; the number of recorded responses therefore exceeded that of the participants. Items were themed by two authors and the inter-rater reliability was tested using the Cohen's Kappa measurement of inter-rater agreement; this produced a score of 0.940 (max. score 1) indicating near-identical coding. The percentage of responses were then calculated for each theme and pre- and post-visit percentages were compared to identify how theme responses changed following a zoo visit. To identify the key overarching themes for a more detailed analysis, only the top five most represented themes were retained for analyses, each one representing a minimum of $9 \%$ of the total responses. All other responses were re-coded into the category 'other valid answer'.

To test for an association between visit type and CA response in the pre- and post-visit dataset, the frequency of each response was calculated. In the pre-visit dataset, only 'climate change', 'habitat protection' and 'no valid response' themes had frequencies $>5$ and were therefore eligible for analysis using the Chi-squared test. In the post-visit dataset, only two response codes (sustainable fishing and no valid response) were eligible for analysis. These response options were subsequently tested using a z-test for difference in proportions among visit types with a Bonferroni correction (separate tests were run for the pre- and the post-visit datasets).

\section{Results}

Of 180 pre-visit questionnaires completed, 134 (74.4\%) participants completed the post-visit questionnaire; $26(19.4 \%)$ took part in an 'encounter', 36 (26.9\%) attended the 'penguin parade', 58 (43.3\%) participated in 'exhibit viewing' and 14 participants (10.4\%) comprised the 'control' group. Participants who did not complete a post-visit questionnaire were excluded. No data were available to determine the reasons for non-completion by these excluded participants. The chi-squared tests showed no detectable difference $(p>0.05)$ in age or gender between visit types. Of 134 participants, 80 were female, 52 were male and two preferred not to say. Most participants were between 20 and 39 years (87 participants). Thirty-five participants were between 40 and 59 years of age, and 11 were between 60 and 79 years of age, although one person did not provide their age.

\subsection{Pro-Environmental Behaviours}

The proportion of responses to each PEB rating scale item in either the pre- or postvisit questionnaires was compared across visit types (Figure 2). No differences were detectable between groups at either of the sampling points. Since the questions asked at the two sampling points were not identical (i.e., behaviours performed versus intention to perform behaviours) no statistical analyses were performed. However, a numerical increase in intention to perform each behaviour was observed in the post-visit responses overall. There was an average increase in intention to perform positive behavioural changes for buying sustainable fish/encouraging others to do so (0.7. $\mathrm{SD} \pm 1.24$ ); volunteering for conservation (1.56. $\mathrm{SD} \pm 1.16)$; telling friends what they can do to help conserve wildlife (1.04. SD \pm 1.03$)$; using re-usable shopping bags $(0.16 . \mathrm{SD} \pm 0.48)$ and donating money to conservation (0.37. SD \pm 1.02$)$. 


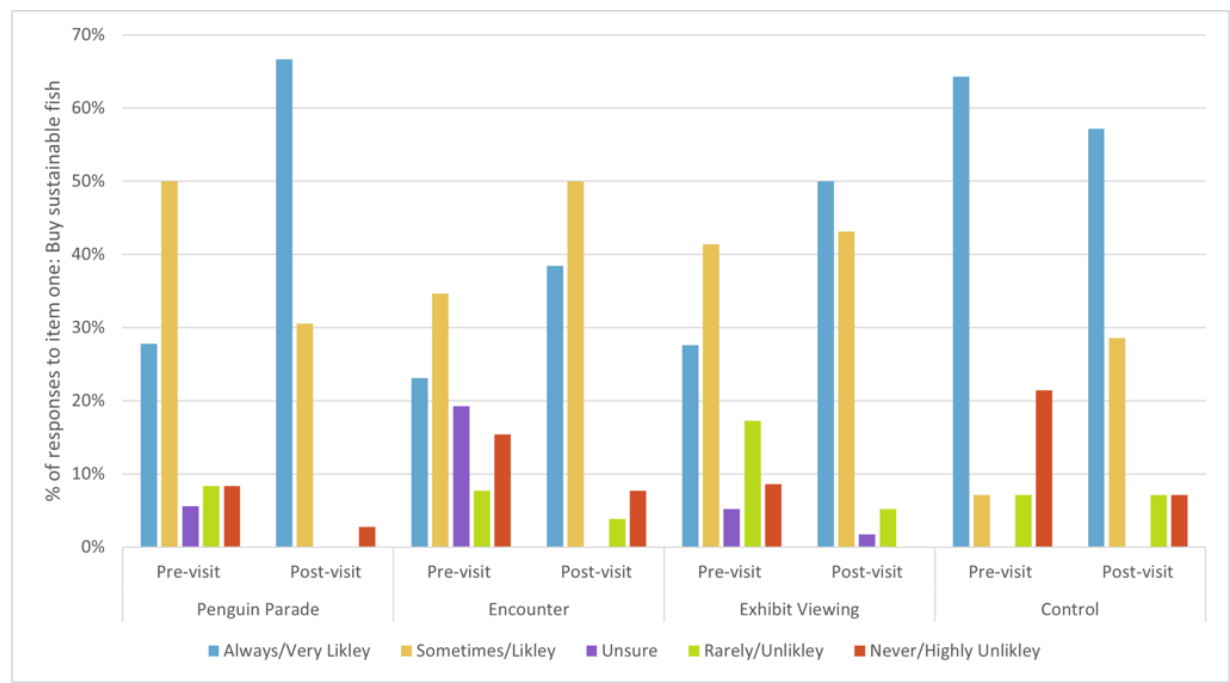

(a)

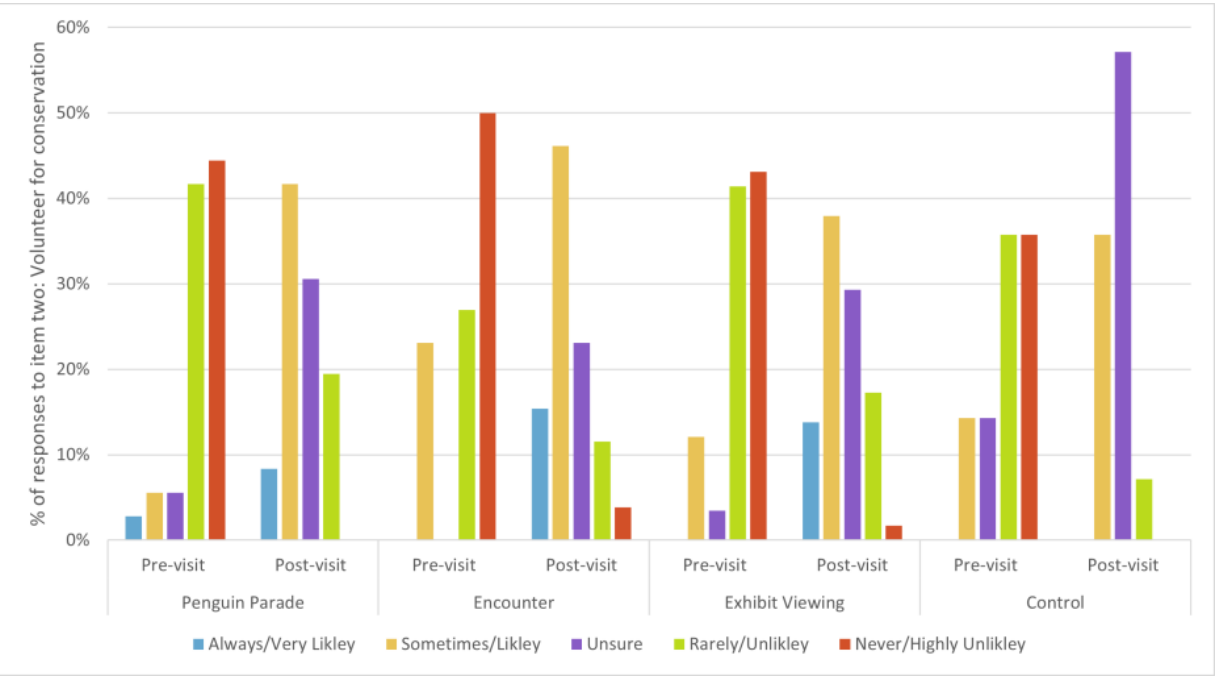

(b)

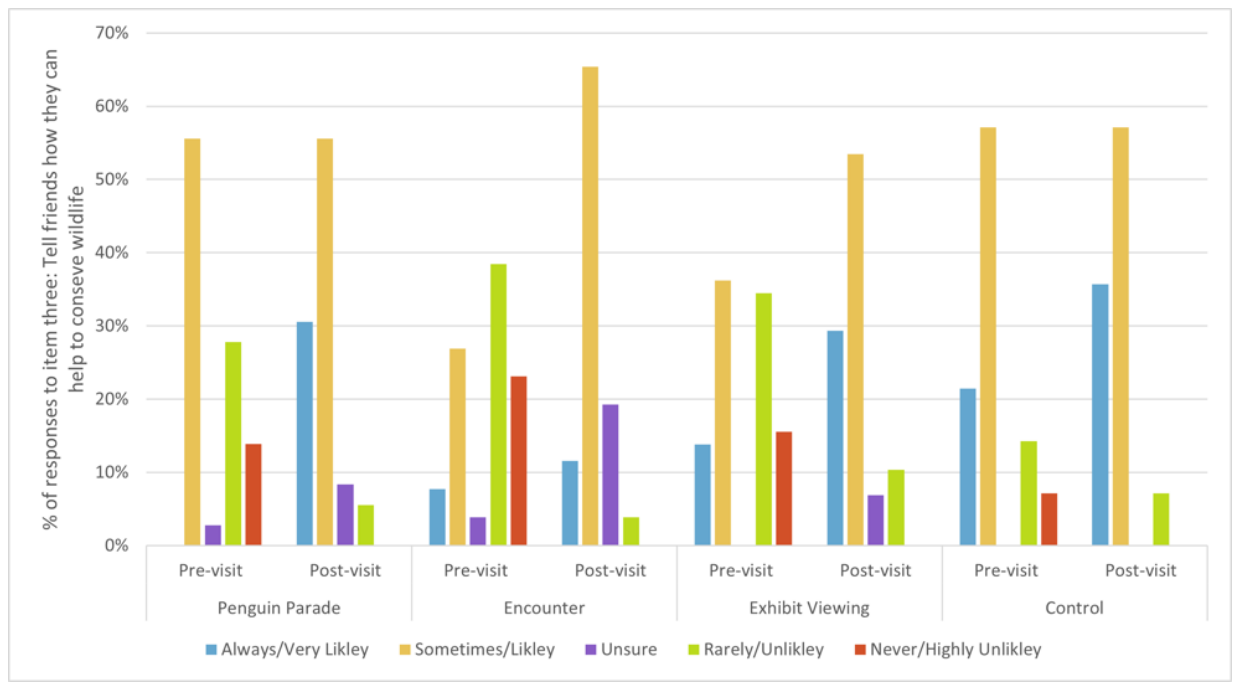

(c)

Figure 2. Cont. 


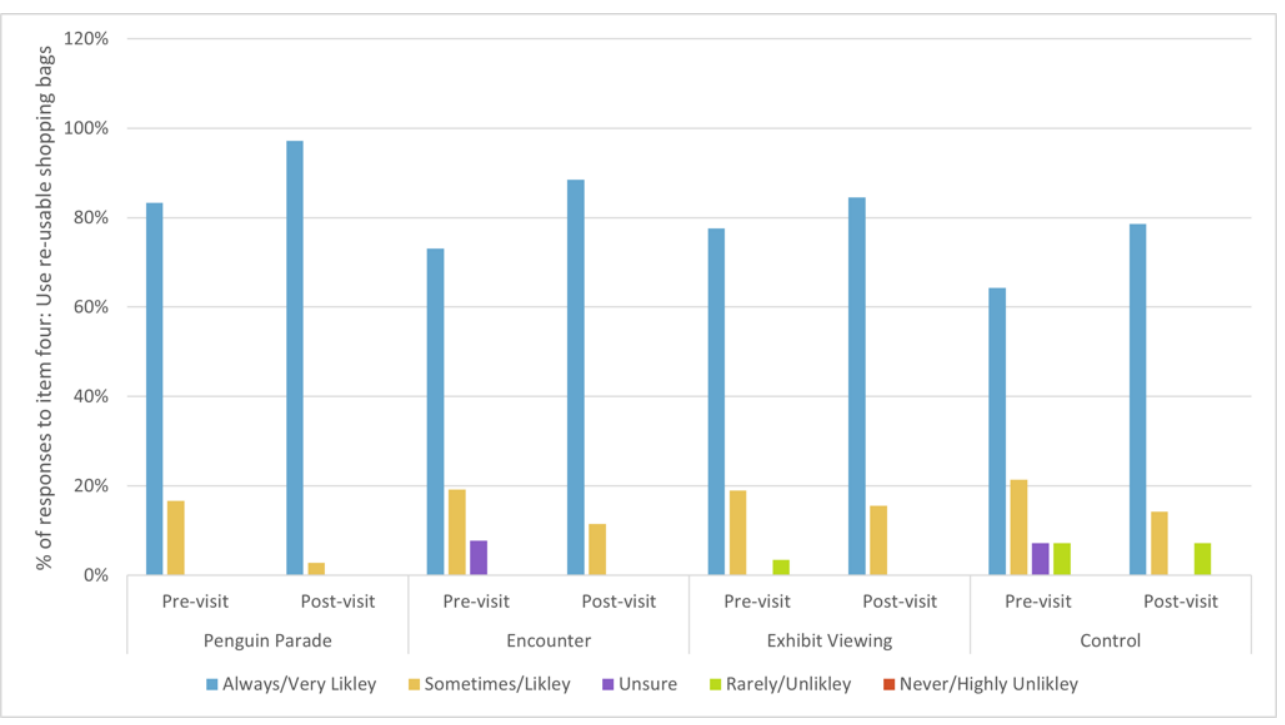

(d)

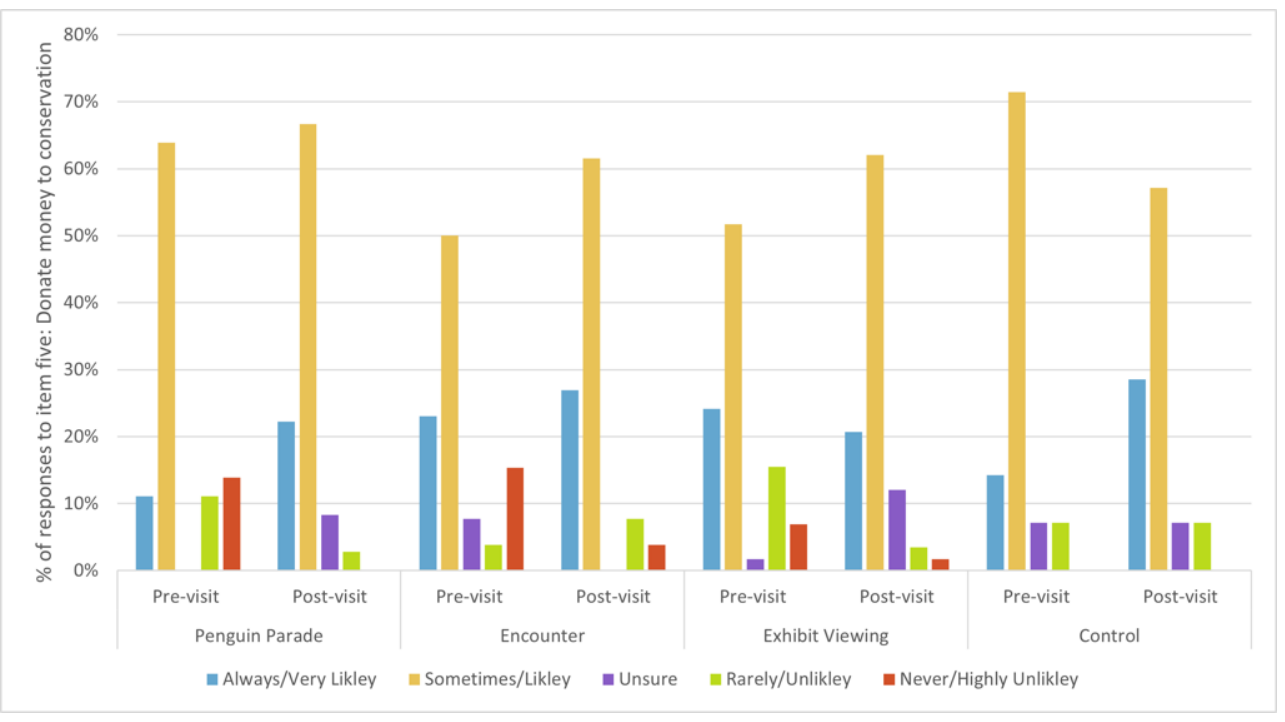

(e)

Figure 2. Percentage of responses belonging to each Likert category (where $1=$ always and $5=$ never in the pre-visit questionnaire, and $1=$ very likely and $5=$ highly unlikely) in the post-visit questionnaire completed by zoo visitors classified as having had one of four types of visit (viewed a penguin parade, had a penguin encounter, viewed the penguin exhibit or none of these experiences (control)).Answers were provided in response to how often they already/are likely to (a) buy sustainable fish, (b) volunteer for conservation, (c) tell friends how they can help to conserve wildlife, (d) use re-usable shopping bags and (e) donate money to conservation, pre- and post-visit.

No significant difference was found in baseline rating scale responses $(p>0.05)$ given in the pre-visit questionnaire between visit type groups on a question-by-question basis. The same test was conducted on post-visit rating scale items and no significant difference $(p>0.05)$ was found between visit type responses in these data either.

\subsection{Conservation Actions}

When asked to list a specific CA for the Humboldt Penguin, 155 unique responses were recorded pre-visit and 156 in the post-visit questionnaires (Table 3). However, 33.6\% of participants in the pre-visit and $29.1 \%$ of participants in the post-visit questionnaire provided invalid answers. Notable changes were identified for responses related to climate 
change and increasing sustainable fishing (Table 3). In the pre-visit questionnaire, $24.7 \%$ of responses were related to climate change compared to just $7.1 \%$ in the post-visit questionnaire. In contrast, responses related to ensuring fishing stocks are sustainable increased from $10.4 \%$ in the pre-visit to $41.3 \%$ in the post-visit questionnaire.

Table 3. Percentages of overarching themes that were identified, as coded by the authors, from responses provided to the open-ended question 'Can you list any specific conservation actions you can take for the Humboldt Penguin' asked of participants visiting a zoo in a pre- $(n=154)$ and post-visit $(n=155)$ questionnaire.

\begin{tabular}{|c|c|c|c|c|}
\hline Overarching Theme & $\begin{array}{l}\text { No. of Pre-Visit } \\
\text { Responses }(n)\end{array}$ & $\begin{array}{l}\text { \% Of Pre-Visit } \\
\text { Responses }\end{array}$ & $\begin{array}{l}\text { No. of Post-Visit } \\
\text { Responses }(n)\end{array}$ & $\begin{array}{l}\% \text { Of Post-Visit } \\
\text { Responses }\end{array}$ \\
\hline No valid answer & 45 & 29.2 & 40 & 25.8 \\
\hline Climate Change & 38 & 24.7 & 11 & 7.1 \\
\hline Sustainable fishing & 16 & 10.4 & 64 & 41.3 \\
\hline Reduce, Reuse, Recycle & 9 & 5.8 & 16 & 9.7 \\
\hline Ex situ conservation breeding & 10 & 6.5 & 5 & 3.2 \\
\hline $\begin{array}{c}\text { Charitable or general support of } \\
\text { zoos and aquariums }\end{array}$ & 9 & 5.8 & 9 & 5.8 \\
\hline Ecotourism & 1 & 0.6 & 1 & 0.6 \\
\hline Hunting ban/guano usage ban & 2 & 1.3 & 1 & 0.6 \\
\hline $\begin{array}{l}\text { Habitat protection/Environmental } \\
\text { conservation }\end{array}$ & 15 & 9.7 & 5 & 3.2 \\
\hline $\begin{array}{l}\text { Education/ } \\
\text { awareness }\end{array}$ & 5 & 3.2 & 3 & 1.9 \\
\hline Regulations & 2 & 1.3 & 1 & 0.6 \\
\hline $\begin{array}{l}\text { Avoiding removal of animals from } \\
\text { natural habitat }\end{array}$ & 2 & 1.3 & 0 & 0.6 \\
\hline
\end{tabular}

For groups eligible for chi-squared analysis, no significant association was found between visit type and any of the tested CA themes for pre-visit data. Within the postvisit response dataset, no significant association between the visit type and whether the visitors provided a valid response was detected. However, a significant association was found within post-visit responses between the visit type and whether responses related to sustainable fishing $(p=0.017)$. A Bonferroni correction test determined that the proportion of visitors mentioning sustainable fishing was significantly higher $(p<0.05)$ in the 'exhibit viewing' group compared with the 'control', but no difference was found for any other pair-wise comparison ( $p>0.05$ in all cases).

Only seven participants gave an identical valid answer in the pre- and post-visit questionnaires. Five participants who had not given a valid answer in the pre-visit questionnaire provided a valid response in the post-visit questionnaire. Overall, 87 participants (64.9\%) changed their response to the question 'Can you list any specific conservation actions you can take for the Humboldt Penguin?' following their zoo visit. The key CA themes identified (i.e., with responses representing $>9 \%$ ) in the pre-visit questionnaire were: 'No valid answer', 'Climate change', 'Sustainable fishing' and 'Habitat protection/Environmental Conservation'. These changed in the post-visit survey to include the additional key theme of 'reduce, reuse, recycle' (Figure 3).

Answers provided were also categorised into overarching and personally achievable actions as defined in the Section 2. No significant association $(p>0.05)$ was found between visit types and whether a personally achievable action or overarching theme was reported in post-visit open-ended responses. 


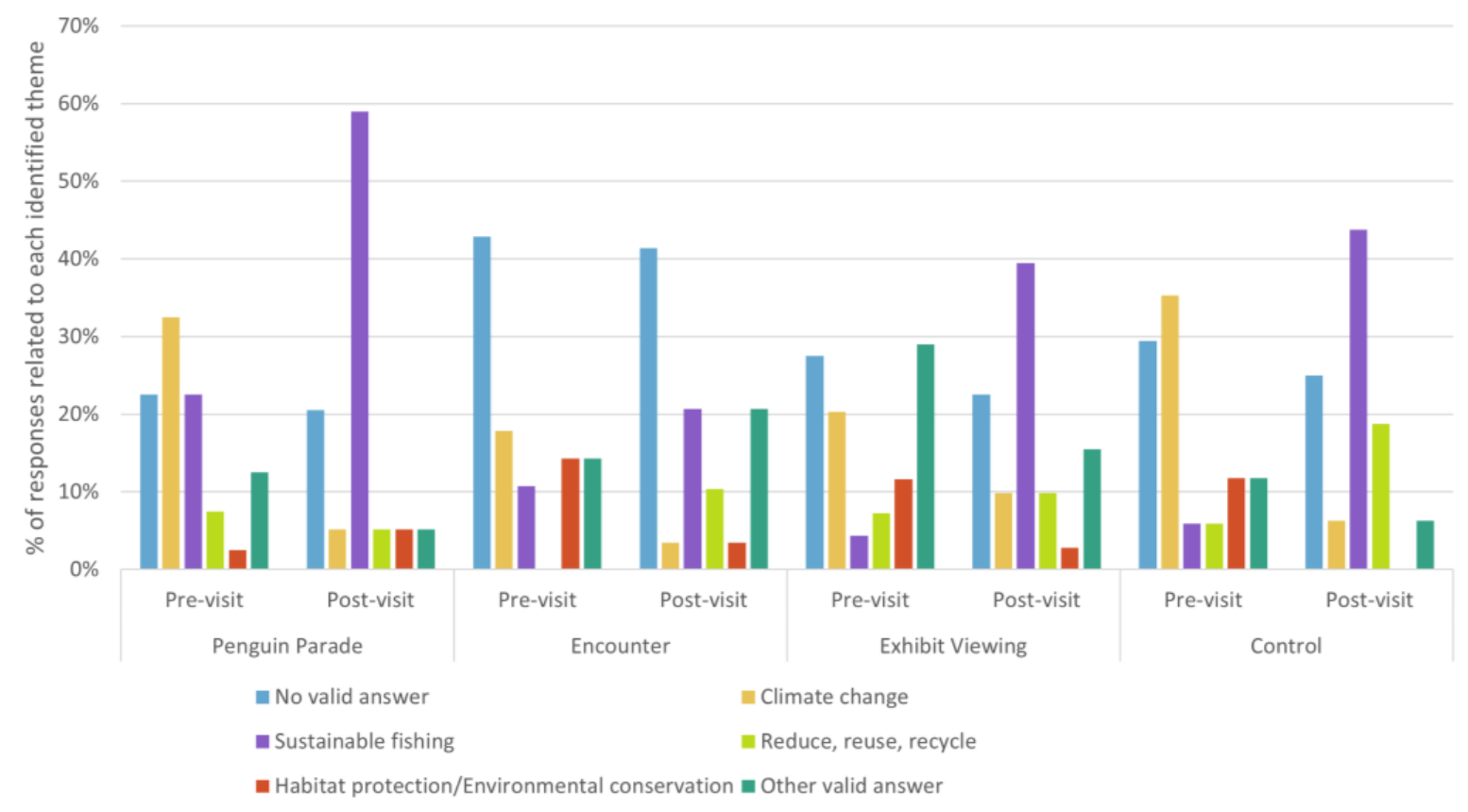

Figure 3. Percentages of themes derived from open-ended responses to the question 'can you think of any specific actions that can be taken for the Humboldt penguin?' belonging to each of the stated overarching themes in the pre- $(n=154)$ and post-visit $(n=155)$ questionnaires administered before and after a zoo visit, grouped by visit type.

\section{Discussion}

Using visitor experiences involving ambassador Humboldt penguins at Twycross Zoo, this study assessed the influences of CE experiences on visitor intentions to perform and knowledge of PEBs and if their experience type influenced these factors. A numerical increase in the intention to perform PEBs was observed between pre- and post-visit, suggesting the zoo visit positively impacted PEB intentions overall. However, the extent of intention was not affected by the type of experience. Overall change in the knowledge of PEB was also found from pre- to post-visit responses. This included a notable increase in responses related to sustainable fishing and a decrease in those related to climate change from pre- to post-visit responses in all responses given. There were significantly more responses related to sustainable fish post-visit in the 'exhibit viewing' group compared with the 'control' group, although no other significant differences were found. As sustainable fishing is a key focus of the Twycross Zoo's Penguin CE programmes, these results provide promising evidence that animal ambassadors and CE materials can positively influence visitor engagement with messaging on this topic. However, the use of more involved animal experiences appeared to be unnecessary in achieving this, which calls into question their role within CE. It is clear that CE efforts have made positive impacts on PEB, as has the use of the ambassador species as a focal point for advertising CE goals, although the use of close encounters may not be necessary.

\subsection{Intention to Perform Pro-Environmental Behaviours}

Intention to perform PEBs increased regardless of experience type across all tested PEBs, indicating a positive impact of CE based in the zoo environment. This supports previous research including Schonfelder et al. [57] and Seybold et al. [58] who found higher levels of interest and knowledge retention of conservation information in students who visited an animal attraction compared to those who received a classroom session. Wu et al. [59] discussed the role of context within PEB uptake, finding that the perceived available infrastructure to perform a behaviour is influential of behavioural uptake. They found that individuals were more engaged in PEB education within the home than in a 
nature-based tourism attraction, possibly due to this being perceived as more achievable to them in their daily lives. Our finding that 'using reusable shopping bags' was the most commonly selected PEB performed 'always' or 'sometimes' in the pre-visit questionnaire (Figure 2),aligns with this. In the current study, a greater intention to participate in behaviours requiring minimal change to routine and cost (e.g., using re-usable shopping bags, telling friends about conservation or buying sustainable products) following the zoo visit was observed. In contrast, voluntary work was the least popular pre-visit activity, and the zoo visit had no impact on the intention to perform this PEB, with most indicating they were 'unsure' if they would take up this PEB. This may be due to time constraints or an uncertainty of how to perform this PEB or indeed what perceived positive impacts such activities may have. This can be further supported by the Theory of Planned Behaviour, whereby a perceived consequence of performing a behaviour influences the likelihood to perform it $[44,45]$. If participants feel their actions will not have significant consequence, they could be less likely to perform them. The value belief norm theory suggests that creating clear pathways between the values, beliefs and actions of an individual will increase understanding and a sense of obligation to perform behaviours $[19,60]$. Without certainty of the effects of their actions whilst performing a PEB such as volunteering, a key element creating intention is missing, which could explain the lower intention for this behaviour overall. Similarly, answers relating to donating money remained largely constant pre- and post-visit, possibly due to the inferred personal costs which have been found to influence likelihood to perform PEBs in other studies [61,62]. Whilst this research highlights potential trends in types of PEB, it did not explore the reasoning behind differences in response for different PEBs. Future research to explore participants' motivations may enable zoos to capitalise on the most effective topics to target when developing new interpretive materials.

\subsection{Influence of Experience Type on Intention to Perform PEBs from Pre- to Post-Visit Responses}

Across all groups, an increased number of participants were 'likely' or 'very likely' to purchase or tell others about sustainable fish options. A larger increase was seen in the 'parade' group, potentially related to the spoken information being associated with improved CE outcomes. For example, Mellish et al. [38] found visitors attending an educational seal show with spoken information were 8.75 times more likely to learn something new and 23.54 times more likely to recall specific conservation actions than those who visited a self-interpreted exhibit. In another study, visitors who attended a presentation about survival plans of species reported increases in recycling, turning off lights and unplugging electronics than those who did not view the presentation [41]. Several studies have identified higher reports of visitor satisfaction as well as conservation mindedness when they witnessed a high behavioural diversity of animals at close range or physically interacted with them $[27,28,30,38,63]$.

Staff interaction often occurs simultaneously to a visitor viewing or handling an ambassador animal, facilitating the provision of information by staff during situations where interpretive signage is often ignored [32]. Visitors who attended an elephant talk did not express increased conservation intent but those who interacted with a staff member did [30] and when families engaged with a staff member whilst viewing orangutans (Pongo spp.), themes of conservation were discussed more frequently, although these themes ceased once interaction was finished [31]. In contrast to this previous research, the 'encounter' group in this study elicited no greater behavioural intention than other groups, despite their closer contact to animals and their personal interactions with staff. This indicates that the additional interaction available during the 'encounter' visits was unsuccessful in stimulating additional changes in visitor PEBs. This is possibly due to the distraction from conservation messages through active participation and concentration on feeding the animals over learning about them. Given there was no evidence for increased intention to perform PEBs following an encounter, justification for this type of zoo visitor experience requires that the welfare of animals involved is not compromised. Any tradeoff between animal welfare and CE goals must be examined carefully. Whilst this study 
did not investigate animal welfare parameters and therefore cannot speculate as to the impact of these encounters on the penguins involved, recent research elsewhere [64] has determined no effect of close contact between visitors and penguins on penguin or colony behaviour. It could be argued that the Penguin Parade still meets the criteria of close animal encounters, even though physical contact with the animals was excluded, and was sufficient to generate motivation for change in PEB. Furthermore, staff-led discussion with visitors at the parade could explain their higher PEB intention. Considering these points, specifically embedding CE messaging into all encounters that require active participation or physical contact with animals, rather than relying on passive learning of the participants depending on the questions they ask or presentations they hear in the background, could be beneficial in improving such programmes. This could be considered at the point of animal encounter programme design, whereby specific prescribed messages and information must be conveyed to participants as part of their experience.

In support of our finding of a relative lack of effect of the encounter on visitor PEB intention, touch pool encounters have been reported to encourage more basic scientific reasoning, rather than higher level understanding required for behavioural change [65], albeit without the use of a control or pre-encounter data. Since the present study included a control group, its validity is improved; participants in the 'control' group provided relatively stable responses (from pre- to post-visit), suggesting minimal response bias existed in the study. However, the 'encounter' group represented the smallest sample size, and larger samples will be necessary to confirm these findings.

Although numerically it appears that for some questions the increase in intent from pre- to post-visit responses was higher in some groups than others, this was not found to be statistically significant.

\subsection{Influence of Experience Type on Intention to Perform PEBs in the Post-Visit Responses}

Although our findings highlight the positive impacts of CE on behaviour intentions overall, no evidence for a role of experience type was detected when visitors were compared post-visit (note this differs to change in behavioural intention which was noted in Miller et al., [28] and Garcia-Cegarra and Pacheco [66]). It is also important to consider that intent to perform behaviours does not always translate to action. In a study by Ballantyne et al., [43] as low as 7\% of participants engaged in new conservation activities because of their visit to animal attractions. This is further supported by Foster [41] and Hughes [42] who suggested that generally knowledge retention is higher than the uptake of conservation behaviours. Likewise, if intent is not translated into meaningful action, it could be argued that the aims of CE have not been met. It must also be considered that the limited difference between responses from individuals of differing experience types could be influenced by social desirability bias, where participants may not be truthful with their responses if they conflict with social norms and could be perceived as undesirable. This is particularly seen when subjective topics are being measured $[43,67,68]$. The present study used an interview style to mitigate the loss of data through missed questions, although participants answered on an answer sheet rather than aloud. Indirect sampling techniques typically yield results closer to the truth as it adds an element of anonymity, thus increasing willingness to answer truthfully [54]. Allowing visitors to non-verbally respond was related to the theme of indirect answering as part of the effort to mitigate social desirability bias.

\subsection{Knowledge of Conservation Actions}

Proportions of open-ended responses relating to sustainable fishing were significantly higher in the 'exhibit viewing' group compared to the 'control' group following a zoo visit. As significant differences in the pre-visit responses were not detected, it is likely that this post-visit difference between groups was at least partially influenced by the experience type undertaken. This finding gives support for the efficacy of self-led interpretation and the effectiveness of signage and other interpretation material at the zoo and has been documented elsewhere previously [69]. Signage provided at Twycross Zoo includes key 
pieces of information in short and clear bullet points, which may have assisted guests in accessing key information quickly and easily whilst they observed the animals in their enclosure. However, the finding that the more interactive experiences ('penguin parade' and 'encounter') were unable to elicit differences in CA knowledge among participants is contradictory to some previous research $[28,38,70]$. This could be due to differences in staff presenting information. Although each staff member's presentation may have differed slightly, variation was controlled somewhat by the use of scripted key information that must be conveyed by every staff member during talks; it is therefore unlikely that interpresenter variation would be a key contributing factor. The lack of differences between groups could also be a seasonal effect. This study was carried out in the winter which suggests that visitors may have had pre-existing interests in the animals (i.e., in order to increase motivation for visiting during the cold weather). More research is required to investigate these factors and it is recommended that additional data on presenters and participant demographics are collected in future studies to explore their effects. A sample of 134 was used within this study which is small compared to other large-scale studies [71-73] and sample sizes within different experience categories were unequal. Whilst a large sample size was obtained for the 'exhibit viewing' group, a comparatively small sample for the 'control' was obtained.

Although no other significant associations were found, there was an overall increase in responses related to sustainable fish from $10.4 \%$ in the pre-visit to $41.3 \%$ in the postvisit questionnaire across all visit types. In contrast, responses relating to climate change decreased from $24.7 \%$ to $7.1 \%$ in the between pre- and post-visit responses. Although climate change is mentioned on other interpretive materials around the zoo, it is not an explicit focus during the penguin presentations or on the penguin signage whereas sustainable fish is, which may explain the shift. There are other indications in previous research where the knowledge or PEB intention change has been in line with the specific themes related to the CE they were exposed to [74-76], offering support for the efficacy of CE. In this study, by using a repeated-measures design, we were able to clearly highlight the change in the theme of responses from pre- to post-visit, indicating that the zoo visits influenced knowledge of conservation actions relating to the Humboldt Penguin. Whilst this highlights an improvement in knowledge and intention to perform PEBs, actual behaviour change following zoo visits could not be measured. It is recommended that future studies utilise a follow up study following the zoo visit to capture this information.

Open-ended responses have been found to provide a more in depth understanding of people's knowledge and attitudes toward a prescribed topic than closed responses $[39,70]$ although these are more subjective and difficult to interpret. It must be considered that increases in knowledge observed could be explained by the concept of priming; focus of attention in working memory suggests people perform better in tests when their attention is drawn to test-relevant content prior to the test [77]. This is further supported by similar increases in the 'control' group, although changes were not significant. Pre-visit responses were completely 'ad hoc' whereas visitors were expecting a post-visit questionnaire and had the duration of their visit to focus their attention on the available information. As part of the attempt to reduce potential bias via priming, additional questions were used in the pre-visit questionnaire directed at alternative animal ambassador species that were not the focus of this study (and were not subsequently analysed). This aimed to reduce the risk that participants would actively seek out penguin information in advance of their post-visit questionnaire.

Although experience type did not overall have significant effects on open-ended responses, except for sustainable fishing which was the most advertised theme within the zoo, it is likely that penguin CE materials in general have influenced the increase in sustainable fishing responses. However, seeking information about which participants actually viewed interpretive signage, who spoke with staff directly and their frequency of zoo visits or membership, for example, may aid in understanding the influences on CA knowledge retention. As discussed by Mellish et al. [78] other limitations of similar 
studies include the overrepresentation of Western country of origin samples which may overlook potential cultural differences in the results. Experiences and interpretations differ between establishments making a multi-establishment analysis difficult; however, extending research to multiple countries may highlight important differences in visitor views that may allow $\mathrm{CE}$ to be developed in a way that will be more effective and relatable to the audiences of that establishment. The results from the current study should not be extrapolated without caution to other cultures and geographic regions due to these potential differences.

\section{Conclusions}

Overall, this study has highlighted that zoo visitors gained specific conservationbased knowledge and had higher behavioural intentions towards PEBs following their zoo visit. However, this study found no evidence to support previous claims that close contact interactions between visitors and animals improved CE outcomes (as measured by PEB intention) beyond that achieved by other zoo experiences. To ensure best practice is followed and CE outcomes are considered equally alongside ambassador animal welfare concerns, further research is recommended.

Author Contributions: Conceptualization, M.M.C.-C. and K.W.-T.; methodology, M.M.C.-C., K.W.-T. and C.F.E.; formal analysis, M.M.C.-C.; investigation, M.M.C.-C.; resources, M.M.C.-C., K.W.-T. and C.F.E.; data curation, M.M.C.-C.; writing-original draft preparation, M.M.C.-C.; writing-review and editing, K.W.-T. and C.F.E.; visualization, M.M.C.-C.; supervision, K.W.-T.; project administration, M.M.C.-C. and K.W.-T.; funding acquisition, K.W.-T. and M.M.C.-C. All authors have read and agreed to the published version of the manuscript.

Funding: This research received partial funding from the School of Animal, Rural and Environmental Sciences, Nottingham Trent University.

Institutional Review Board Statement: The study was conducted according to the guidelines of the Declaration of Helsinki and approved by the Institutional Review Board (or Ethics Committee) of Nottingham Trent University (protocol code ARE695 in October 2017).

Informed Consent Statement: Informed consent was obtained from all subjects involved in the study.

Data Availability Statement: Anonymised data will be made available upon request.

Acknowledgments: We would like to thank Twycross Zoo (East Midlands Zoological Society) for the use of their facilities without which this study would not have been possible. Thanks must go to Samantha Clifford for investing her time and interest to be a research assistant during data collection.

Conflicts of Interest: At the time of study, two of the authors were employed by Twycross Zoo. This research was not commissioned by Twycross Zoo, and all research was conducted independently and during non-working hours/days of the zoo role for which they were employed. The research was conducted as part of the first author's post-graduate study.

\section{References}

1. Whitehouse-Tedd, K.M.; Spooner, S.; Scott, L.; Lozano-Martinez, J. Animal Ambassador Encounter Programmes in Zoos: Current Status and Future Research Needs. In Zoo Animals: Husbandry, Welfare and Public Interactions; Berger, M., Corbett, S., Eds.; Nova Science Publishers: New York, NY, USA, 2018; Chapter 2; pp. 89-140.

2. Whitehouse-Tedd, K.M.; Spooner, S.; Whitehouse-Tedd, G. Making training educational for zoo visitors. In Zoo Animal Learning and Training; Ward, S., Melfi, V., Dorey, N., Eds.; Wiley: Blackwell, NJ, USA, 2020; Chapter 10.

3. Thomas, S. Social Change for Conservation: The World Zoo and Aquarium Conservation Education Strategy; WAZA Executive Office: Barcelona, Spain, 2020; p. 89.

4. $\quad$ Díaz, S.; Settele, J.; Brondízio, E.S.; Ngo, H.T.; Guèze, M.; Agard, J.; Arneth, A.; Balvanera, P.; Brauman, K.A.; Butchart, S.H.M.; et al. (Eds.) IPBES, 2019: Summary for Policymakers of the Global Assessment Report on Biodiversity and Ecosystem Services of the Intergovernmental Science-Policy Platform on Biodiversity and Ecosystem Services; IPBES Secretariat: Bonn, Germany; p. 56. Available online: https:/ /ipbes.net/system/tdf/ipbes_global_assessment_report_summary_for_policymakers.pdf?file=1\&type=node\& id=35329 (accessed on 7 January 2020).

5. Williamson, K.; Satre-Meloy, A.; Velasco, K.; Green, K. Climate Change Needs Behaviour Change: Making the Case for Behavioural Solutions to Reduce Global Warming; Rare: Arlington, VA, USA, 2018. 
6. Kothe, E.J.; Ling, M.; North, N.; Klas, A.; Mullan, B.A.; Novoradovskaya, L. Protection motivation theory and pro-environmental behaviour: A systematic mapping review. Aust. J. Psychol. 2019, 71, 411-432. [CrossRef]

7. Feilen, K.L.; Guillen, R.R.; Vega, J.; Savage, A. Developing successful conservation education programs as a means to engage local communities in protecting cotton-top tamarins (Saguinus oedipus) in Colombia. J. Nat. Conserv. 2018, 41, 44-50. [CrossRef]

8. Gusset, M.; Dick, G. The global reach of zoos and aquariums in visitor numbers and conservation expenditures. Zoo Biol. 2011, 30, 566-569. [CrossRef] [PubMed]

9. Collins. Definition of Zoo. 2020. Available online: https://www.collinsdictionary.com/dictionary/english/zoo (accessed on 7 January 2020).

10. WAZA. Mission Statement. 2015. Available online: https://www.waza.org/wp-content/uploads/2019/03/WAZAConservation-Strategy-2015_Portrait.pdf (accessed on 18 August 2018).

11. Moss, A.; Esson, M. The Educational Claims of Zoos: Where Do We Go from Here? Zoo Biol. 2012, 32, 13-18. [CrossRef] [PubMed]

12. Ballantyne, R.; Packer, J.; Hughes, K.; Dierking, L. Conservation learning in wildlife tourism settings: Lessons from research in zoos and aquariums. Env. Educ. Res. 2007, 13, 367-383. [CrossRef]

13. Luebke, J.F.; Watters, J.V.; Packer, J.; Miller, L.J.; Powell, D.M. Zoo visitors' affective responses to observing animal behaviours. Visit. Stud. 2016, 19, 60-76. [CrossRef]

14. Yang, X.; Chen, J. Using discovery maps as free-choice learning process can enhance the effectiveness of environmental education in a botanical garden. Environ. Educ. Res. 2015, 23, 656-674. [CrossRef]

15. Dove, T.; Byrne, J. Do Zoo Visitors need Zoology Knowledge to Understand Conservation Messages? An Exploration of the Public Understanding of Animal Biology and of the Conservation of Biodiversity in a Zoo Setting. Int. J. Sci. Educ. Part B 2013, 4 323-342. [CrossRef]

16. Falk, J.H. Free-choice environmental learning: Framing the discussion. Environ. Educ. Res. 2006, 11, 265-280. [CrossRef]

17. Carr, N. Zoos and animal encounters: To touch or not to touch, that is the question. In Wild Animals and Leisure: Rights and Wellbeing; Carr, N., Young, J., Eds.; Routledge: New York, NY, USA, 2018.

18. Skibbins, J.C.; Powell, R.B. Conservation caring: Measuring the influence of zoo visitors' connections to wildlife on proconservation behaviours. Zoo Biol. 2013, 32, 528-540. [CrossRef]

19. McGowan, J.; Beaumont, L.J.; Smith, R.J.; Chauvenet, A.L.M.; Harcourt, R.; Atkinson, S.C.; Mittermeier, J.C.; Esperon-Rodriguez, M.; Baumgartner, J.B.; Beattie, A.; et al. Conservation prioritization can resolve the flagship species conundrum. Nat. Commun. 2020, 11, 994. [CrossRef]

20. Association of Zoos and Aquariums. Ambassador Animals. 2018. Available online: https://www.aza.org/ (accessed on 17 August 2018).

21. Watters, J.V.; Powell, D.M. Measuring Animal Personality for Use in Population Management in Zoos: Suggested Methods and Rationale. Zoo Biol. 2012, 31, 1-12. [CrossRef]

22. Fuhrman, N.; Rubenstein, E. Teaching with Animals: The Role of Animal Ambassadors in Improving Presenter Communication Skills. J. Agric. Educ. 2017, 58, 223-235. [CrossRef]

23. Wünschmann, S.; Wüst-Ackermann, P.; Randler, C.; Vollmer, C.; Itzek-Greulich, H. Learning Achievement and Motivation in an Out-of-School Setting-Visiting Amphibians and Reptiles in a Zoo Is More Effective than a Lesson at School. Res. Sci. Educ. 2017, 47, 497-518. [CrossRef]

24. Mann-Lang, J.B.; Ballantyne, R.; Packer, J. Does more education mean less fun? A comparison of two animal presentations. Int. Zoo Yearb. 2016, 50, 155-164. [CrossRef]

25. Price, A.; Boeving, E.R.; Shender, M.A.; Ross, S.R. Understanding the effectiveness of demonstration programs. J. Mus. Educ. 2015, 40, 46-54. [CrossRef]

26. Skibbins, J.C. Ambassadors or Attractions: Disentangling the role of flagship species in wildlife tourism. In Animals and Tourism: Understanding Diverse Relationships; Markwell, K., Ed.; Channel View Publications: Bristol, UK, 2015.

27. Powell, D.M.; Bullock, E.V.W. Evaluation of Factors Affecting Emotional Responses in Zoo Visitors and the Impact of Emotion on Conservation Mindedness. Anthrozoös 2014, 27, 389-405. [CrossRef]

28. Miller, L.; Zeigler-Hill, V.; Mellen, J.; Koeppel, J.; Greer, T.; Kuczaj, S. Dolphin Shows and Interaction Programs: Benefits for Conservation Education? Zoo Biol. 2012, 32, 45-53. [CrossRef]

29. Pavitt, A.G. Assessing the effect of zoo exhibit design on visitor engagement and attitudes towards conservation. J. Zoo Aquar. Res. 2019, 7, 186-194. [CrossRef]

30. Hacker, C.E.; Miller, L.J. Zoo visitor perceptions, attitudes, and conservation intent after viewing African elephants at the San Diego Zoo Safari Park. Zoo Biol. 2016, 35, 355-361. [CrossRef]

31. Idema, J.; Patrick, P.G. Family conversations at an orangutan exhibit: The influence of zoo educators. Int. Zoo Educ. Assoc. J. 2016, $52,61-63$.

32. Clayton, S.; Fraser, J.; Saunders, C.D. Zoo experiences: Conversations, connections, and concern for animals. Zoo Biol. 2009, 28, 377-397. [CrossRef]

33. Ogle, B. Value of gest interaction in touch pools at public aquariums. Univers. J. Manag. 2016, 4, 59-63. [CrossRef]

34. Fernandez, E.J.; Tamborski, M.A.; Pickens, S.R.; Timberlake, W. Animal-visitor interactions in the modern zoo: Conflicts and interventions. Appl. Anim. Behav. Sci. 2009, 120, 1-8. [CrossRef] 
35. Baird, B.A.; Kuhar, C.W.; Lukas, K.E.; Amendolagine, L.A.; Fuller, G.A.; Nemet, J.; Willis, M.A.; Schook, M.W. Program animal welfare: Using behavioural and physiological measures to assess the well-being of animals used for education programs in zoos. Appl. Anim. Behav. Sci. 2016, 176, 150-162. [CrossRef]

36. Ballantyne, R.; Packer, J. Visitors' Perceptions of the Conservation Education Role of Zoos and Aquariums: Implications for the Provision of Learning Experiences. Visit. Stud. 2016, 19, 193-210. [CrossRef]

37. Roe, K.; McConney, A. Do zoo visitors come to learn? An internationally comparative, mixed-methods study. Env. Educ. Res. 2015, 21, 865-884. [CrossRef]

38. Mellish, S.; Pearson, E.L.; Sanders, B.; Litchfield, C.A. Marine wildlife entanglement and the Seal the Loop initiative: A comparison of two free-choice learning approaches on visitor knowledge, attitudes and conservation behaviour. Int. Zoo Yearb. 2016, 50, 129-154. [CrossRef]

39. Ballantyne, R.; Hughes, K.; Lee, J.; Packer, J.; Sneddon, J. Visitors' values and environmental learning outcomes at wildlife attractions: Implications for interpretive practice. Tour. Manag. 2018, 64, 190-201. [CrossRef]

40. Jensen, E.A.; Moss, A.; Gusset, M. Quantifying long-term impact of zoo and aquarium visits on biodiversity-related learning outcomes. Zoo Biol. 2017, 36, 294-297. [CrossRef] [PubMed]

41. Foster, S.K. The Effectiveness of Visits to Dickerson Park Zoo on Guests' Conservation Mindedness and Behaviour. Master's Thesis, Missouri State University, Springfield, MO, USA, 2016.

42. Hughes, K. Measuring the impact of viewing wildlife: Do positive intentions equate to long-term changes in conser-vation behaviour? J. Sustain. Tour. 2013, 21, 42-59. [CrossRef]

43. Ballantyne, R.; Packer, J.; Falk, J. Visitors' learning for environmental sustainability: Testing short- and long-term impacts of wildlife tourism experiences using structural equation modelling. Tour. Manag. 2011, 32, 1243-1252. [CrossRef]

44. Ajzen, I. The theory of planned behaviour. Organ. Behav. Hum. Decis. Process. 1991, 50, 179-211. [CrossRef]

45. De Leeuw, A.; Valois, P.; Ajzen, I.; Schmidt, P. Using theory of planned behaviour to identify key beliefs underlying proenvironmental behaviour in high-school students: Implications for educational interventions. J. Environ. Psychol. 2015, 42, 128-138. [CrossRef]

46. Han, H. Travellers' pro-environmental behaviour in a green lodging context: Converging value-belief-norm theory and the theory of planned behaviour. Tour. Manag. 2015, 47, 164-177. [CrossRef]

47. Sultan, P.; Tarafder, T.; Pearson, D.; Henryks, J. Intention-behaviour gap and perceived behavioural control-behaviour gap in theory of planned behaviour: Moderating roles of communication, satisfaction and trust in organic food consumption. Food Qual. Prefer. 2020, 81, 103838. [CrossRef]

48. Mann, J.B.; Ballantyne, R.; Packer, J. Penguin Promises: Encouraging aquarium visitors to take conservation action. Environ. Educ. Res. 2017, 24, 859-874. [CrossRef]

49. Ballantyne, R.; Hughes, K.; Lee, J.; Packer, J.; Sneddon, J. Facilitating zoo/aquarium visitors' adoption of environmentally sustainable behaviour: Developing a values-based interpretation matrix. Tour. Manag. 2021, 84, 104243. [CrossRef]

50. Buckley, K.A.; Smith, L.D.G.; Crook, D.A.; Pillans, R.D.; Kyne, P. Conservation impact scores identify shortfalls in demonstrating the benefits of threatened wildlife displays in zoos and aquaria. J. Sustain. Tour. 2020, 28, 978-1002. [CrossRef]

51. Maxwell-Smith, M.A.; Conway, P.J.; Wright, J.D.; Olson, J.M. Translating Environmental Ideologies into Action: The Amplifying Role of Commitment to Beliefs. J. Bus. Ethics 2016, 153, 839-858. [CrossRef]

52. Jensen, E. Evaluating Children's Conservation Biology Learning at the Zoo. Conserv. Biol. 2014, 28, 1004-1011. [CrossRef]

53. Rowley, J. Designing and using research questionnaires. Manag. Res. Rev. 2014, 37, 308-330. [CrossRef]

54. Rosenfeld, B.; Imai, K.; Shapiro, J.N. An Empirical Validation Study of Popular Survey Methodologies for Sensitive Questions. Am. J. Political Sci. 2015, 60, 783-802. [CrossRef]

55. IBM Corp. IBM SPSS Statistics for Windows; IBM Corp.: Armonk, NY, USA, 2016; Version 24.0.

56. Moss, A.; Jensen, E.; Gusset, M. Evaluating the contribution of zoos and aquariums to Aichi Biodiversity Target 1. Conserv. Biol. 2014, 29, 537-544. [CrossRef]

57. Schönfelder, M.L.; Bogner, F.X. Two ways of acquiring environmental knowledge: By encountering living animals at a beehive and by observing bees via digital tools. Int. J. Sci. Educ. 2017, 39, 723-741. [CrossRef]

58. Seybold, B.; Braunbeck, T.; Randler, C. Primate Conservation- an evaluation of two different educational programs in Germany. Int. J. Sci. Math. Educ. 2014, 12, 285-305. [CrossRef]

59. Wu, J.; Font, X.; Liu, J. The elusive impact of pro-environmental intention on holiday on pro-environmental behaviour at home. Tour. Manag. 2021, 85, 104283. [CrossRef]

60. Caplow, S. The presentation of environmental values, belies and norms in live animal interpretive experiences. Environ. Educ. Res. 2017, 25, 1-16.

61. Zhu, Y.; Wang, Y.; Liu, Z. How does social interaction affect pro-environmental behaviours in China? The mediation role of conformity. Front. Environ. Sci. 2021, 9, 188. [CrossRef]

62. Wi, A.; Chang, C.-H. Promoting pro-environmental behaviour in a community in Singapore-From raising awareness to behavioural change. Env. Educ. Res. 2019, 25, 1019-1037. [CrossRef]

63. Cong, L.; Wu, B.; Morrison, A.M.; Shu, H.; Wang, M. Analysis of wildlife tourism experiences with endangered species: An exploratory study of encounters with giant pandas in Chengdu, China. Tour. Manag. 2014, 40, 300-310. [CrossRef] 
64. Saiyed, S.T.; Hopper, L.M.; Cronin, K.A. Evaluating the Behavior and Temperament of African Penguins in a Non-Contact Animal Encounter Program. Animals 2019, 9, 326. [CrossRef]

65. Kisiel, J.; Rowe, S.; Vartabedian, M.A.; Kopczak, C. Evidence for family engagement in scientific reasoning at interactive animal exhibits. Sci. Educ. 2012, 96, 1047-1070. [CrossRef]

66. García-Cegarra, A.M.; Pacheco, A. Whale-watching trips in Peru lead to increases in tourist knowledge, pro-conservation intentions and tourist concern for the impacts of whale-watching on humpback whales. Aquat. Conserv. Mar. Freshw. Ecosyst. 2017, 27, 1011-1020. [CrossRef]

67. Bryman, A. Social Research Methods; Oxford University Press: Oxford, UK, 2016.

68. Gittelman, S.; Lange, V.; Cook, W.A.; Frede, S.M.; Lavrakas, P.J.; Pierce, C.; Thomas, R.K. Accounting for Social-Desirability Bias In Survey Sampling. J. Advert. Res. 2015, 55, 242-254. [CrossRef]

69. Kelly, A.; Skibbins, J.C. Inspiring wildlife conservation behaviours through innovations in zoo exhibit design. Visit. Stud. 2020, 24, 79-99. [CrossRef]

70. Moss, A.; Jensen, E.; Gusset, M. Impact of a global biodiversity education campaign on zoo and aquarium visitors. Front. Ecol. Env. 2017, 15, 243-247. [CrossRef]

71. Smith, C.; Buckley, N.; Bridges, E.; Pavitt, B.; Moss, A. Self-reported impacts of volunteering in UK zoos and aquariums. Cult. Trends 2018, 27, 18-32. [CrossRef]

72. Grajal, A.; Luebke, J.F.; Kelly, L.D.; Matiasek, J.; Clayton, S.; Karazsia, B.T.; Saunders, C.D.; Goldman, S.R.; Mann, M.E.; Stanoss, R. The complex relationship between personal sense of connection to animals and self-reported pro-environmental behaviours by zoo visitors. Conserv. Biol. 2017, 31, 322-330. [CrossRef]

73. Kelly, L.-A.D.; Luebke, J.F.; Clayton, S.; Saunders, C.D.; Matiasek, J.; Grajal, A. Climate Change Attitudes of Zoo and Aquarium Visitors: Implications for Climate Literacy Education. J. Geosci. Educ. 2014, 62, 502-510. [CrossRef]

74. Lavin, F.V.; Gelcich, S.; Lerdon, X.P.; Bustos, F.M. The role of information in changing tourist's behavioural preferences at the Humboldt penguin reserve in northern Chile. Ocean Costal Manag. 2016, 125, 63-69. [CrossRef]

75. Pearson, E.L.; Lowry, R.; Dorrian, J.; Litch, C.A. Evaluating the conservation impact of an innovative zoo-based educational campaign: 'Don't palm us off' for orang-utan conservation. Zoo Biol. 2014, 33, 184-196. [CrossRef] [PubMed]

76. Cater, C. Any closer and you'd be lunch! Interspecies interactions as nature tourism at marine aquaria. J. Ecotour. 2010, 9, 133-148. [CrossRef]

77. Souza, A.S.; Oberauer, K. In search of the focus of attention in working memory: 13 years of the retro-cue effect. Atten. Percept. Psychophys. 2016, 78, 1839-1860. [CrossRef] [PubMed]

78. Mellish, S.; Ryan, J.C.; Pearson, E.L.; Tuckey, M.R. Research methods and reporting practices in zoo and aquarium conservationeducation evaluation. Conserv. Biol. 2019, 33, 40-52. [CrossRef] [PubMed] 